\title{
Cannabidiol - A Role for COVID-19?
}

\author{
Gerhard Nahler* and Eberhard Pirich \\ CIS Clinical Investigation Support GmbH, Wien, Austria
}

*Corresponding author: Gerhard Nahler, CIS Clinical Investigation Support GmbH, Kaiserstrasse 43, 1070 Wien, Austria.

Received Date: June 24, 2020

Published Date: July 15, 2020

\begin{abstract}
Although the lung is considered as the primary organ affected by SARS-CoV-2, responsible for tissue and organ hypoxia, cerebrovascular complications such as stroke and neurological impairment such as Guillain-Barré syndrome have been repeatedly reported in COVID-19 patients. Many drugs that are currently administered to patients are experimental treatments which poorly cross the blood-brain-barrier. Cannabidiol (CBD) is known since long for reaching high brain levels and for its favourable safety profile. It has been shown to be neuroprotective and anti-inflammatory and has prevented sequelae in various hypoxic-ischemic disease models as well as in animal models of demyelination. In the past, it has been demonstrated that CBD can be safely co-administered with a number of other medications. CBD may be able to prevent and attenuate complications and long-term damages also in COVID-19 patients.
\end{abstract}

Keywords: Anosmia, Anxiety, Cannabidiol, COVID-19, Guillain-Barré syndrome, Hypoxia, Neuroinflammation, Neuroprotection, SARS-CoV-2, Stroke

Abbreviations: CBD: Cannabidiol; CVD: Cerebrovascular Disease; EAE: Experimental Autoimmune Encephalomyelitis; MOG: Myelin Oligodendrocyte Glycoprotein; TMEV: Theilers Murine Encephalitis Virus

\section{Short Communication}

Although the most challenging symptoms of COVID-19 have been related to acute respiratory distress, an increasing number of publications point to the infection of the vascular endothelial cells by SARS-CoV-2, subsequent endotheliitis, thromboembolic complications and impairment of the central and peripheral nervous system among other organs [1-7]. Most worrying are cerebrovascular events and polyneuroradiculitis, both occurring primarily in elderly patients.

Whereas cerebro- and other vascular complications likely result from a global inflammatory response and a hypercoagulable state induced by the infection with SARS-CoV-2, coronaviruses may disseminate to the central nervous system (CNS) through haematogenous spread, retrograde neuronal dissemination, or direct invasion of the olfactory epithelium. In a very recent publication, the Environmental Neurology Specialty Group of the World
Federation of Neurology (ENSG-WFN) concludes that "respiratory failure, the lethal manifestation of COVID-19, responsible for 215,461 deaths worldwide, is probably neurogenic in origin and may result from the viral invasion of cranial nerve I, progressing into rhinencephalon and brainstem respiratory centers" [5]. This is supported by recent autoptic findings of SARS-CoV-2 in olfactory pathways and brainstem [8]. A sudden dysfunction of smell and taste (up to complete anosmia and ageusia) often preceding other symptoms and - most intriguingly - often in the absence of nasal congestion or rhinorrhoea seems to emerge as an early characteristic of SARS-CoV-2 infections; dysosmia has been observed in 70\% to $98 \%$ of the patients, and more often in women then men $[9,10]$. Meanwhile, a wide range of additional neurological and neuropsychiatric symptoms and disorders have been described that include gait alteration, dizziness, seizures, headache, nausea and vomiting, cognitive impairment, inattention, irritability, agitation, confusion, 
disorientation, anxiety, post-traumatic stress, sleep disturbances, depressed mood and even suicidality [11,12]. Although most patients seem to have recovered without experiencing mental illness, in a longer-term potential aftereffects may not be neglected $[13,14]$. Aftereffects of the pandemic are likely affecting also the general population [15].

Among many other signs and symptoms, cerebrovascular events have also been observed. Serious cerebrovascular disease (CVD) such as stroke, sinus thrombosis and cerebral haemorrhage have been reported primarily in patients who were significantly older $(71 \cdot 6 \pm 15 \cdot 7$ years vs. $52 \cdot 1 \pm 15 \cdot 3$ years $)$, with more concomitant disorders and who were more likely to present with severe COVID-19 (84.6\% vs. 39.9\% [16]; in larger samples, ischemic stroke has occurred with an incidence of $1 \%$ to $6 \%$ [17], $2.4 \%$ [3], $2.5 \%$ [18], and 5.8\% [16]. Individual case reports and case series also demonstrate that cerebrovascular events occur primarily in patients aged around 60 years and older [19-22], although ischemic stroke was occasionally observed in previously healthy, younger COVID-19 patients who were 36 years, 45 and 52 years old [2325]. The average of time from SARS-CoV-2 infection to onset of CVD was about 12 days [16]. At present, data are still insufficient for assessing long-term sequelae of intermediary brain hypoxia during COVID-19.

Another manifestation which has been increasingly diagnosed with COVID-19 is the Guillain-Barré syndrome (GBS). GBS and its variant, the Miller-Fisher syndrome, is an autoimmune disorder of the peripheral nervous system, often triggered by acute infections. It manifests as an inflammatory autoimmune polyradiculoneuritis which has been related to a previous bacterial or viral infection (incidence $1 / 100,000$ ); it induces the production of antibodies which react with the myelin sheath of the peripheral nerves, resulting in demyelination and/or axonal injury [26]. By mid of May 2020 , at least 21 cases related to COVID-19 have been reported with a median age of 61 years. Fourteen of these cases occurred in men; this contrasts to reports from the past, where women were more frequently affected [27]. GBS occurred shortly, after a median of 10 days (range 3 to 29 days) after the onset of symptoms [28-37]. This includes a case of polyneuritis cranialis in a 39 year old man [38]

Other encephalopathies that have been observed include severely impaired consciousness [7,39], meningoencephalitis [40], meningitis with convulsions [41], and hemorrhagic necrotizing encephalopathy [42]. All patients were aged above 55 years, except a 24 years old male with meningitis and a positive SARS-CoV-2 test in the cerebrospinal fluid [41]. Less threatening neurological and neuropsychiatric impairments which occurred in patients with COVID-19 are agitation (69\%), confusion (65\%), dysexecutive syndrome (33\%), asthenia (63.3\%), ataxia (69\%), as well as fatigue (26\%-51\%) [9,22]. In addition, 36\% had myalgia, and increased creatine kinase (CK) was present in $33 \%$ of patients [5]. Overall, neurological involvement varies widely between about $15 \%$ to $21 \%$ to $36 \%[2,3,22,43]$, but was more common in patients with more severe disease (45.5\%) than in non-severe patients (30.2\%) [3]. Frequency is very much dependent on the population characteristics and can precede other symptoms by days [16].

Recent publications stressed that many drugs that are currently administered as experimental treatments for COVID-19 poorly cross the blood-brain barrier, among them monoclonal antibodies, (hydroxy-) chloroquine, favipiravir, lopinavir + ritonavir or remdesivir [44], some of them with nervous system side effects that need to be carefully balanced against expected benefits [1]. In contrast to, cannabidiol (CBD) is well supported and known to penetrate in lipophilic brain tissue; this may open the way for CBD as a supportive treatment in inflammatory CNS infections. The potential of CBD and other cannabinoids for the prevention and treatment of tissue damages caused by severe hypoxia incl. ischemic stroke has been repeatedly reviewed [45-47]; it has also been demonstrated in a number of various animal models of cardiac ischemia-reperfusion injury [48-50], renal ischemia-reperfusion injury [51-52], and newborn hypoxic ischemic encephalopathy [53-61]. In addition to protective effects in newborn hypoxic-ischemic encephalopathy, an impressive number of studies in adult animals has demonstrated that CBD can reduce hypoxia-induced brain damages when given either as prevention or as treatment up to about three days after occlusion [55,62-65], protecting animals from long-term sequelae [66]. Nonetheless, confirmation in human subjects is still lacking and no respective studies seem to be ongoing (www.clinicaltrials. gov).

In addition, CBD treatment has also demonstrated myelin protective effects in a wide array of different demyelinating disease models in animals. One of them studied hypomyelination induced by hypoxia / ischemia in the immature brain. When newborn rats were exposed to hypoxic-ischemic injury, the subsequent treatment with CBD (1mg s.c. $/ \mathrm{kg}$ ) completely preserved function and myelination, suggesting a general neuroprotective effect [56]. In another model, experimental autoimmune encephalomyelitis (EAE) was induced in mice by injection of myelin oligodendrocyte glycoprotein (MOG35-55 peptide) as antigen; mice progressively developed EAE disease, mimicking the inflammatory lesions on the myelin sheath in multiple sclerosis. The disease typically follows the course of a progressive degeneration, with visible signs of pathology consisting of flaccidity of the tail and loss of motion of the hind legs. It was found that intraperitoneal administration of CBD (20mg i.p./kg) delayed the onset of disease and significantly attenuated clinical signs of EAE, proliferation of MOG-specific T-cells, and also significantly reduced inflammatory cytokine levels of IFN $\gamma$ and IL-17. A dose of $20 \mathrm{mg} / \mathrm{kg}$ body weight of CBD translates to $1.6 \mathrm{mg} / \mathrm{kg}$ when converted to human equivalent dose [67]. Furthermore, CBD reduced autoimmune encephalomyelitis also in a model of adoptively transferred EAE. When splenocytes and lymph nodes from mice with actively induced EAE were cultured in the presence of MOG3555 and IL-12, and inoculated intraperitoneally in recipient mice, EAE is adoptively transferred to recipients (at-EAE); CBD proved to 
be effective also in this model [68]. Using the same model, another group of researchers could demonstrate that treatment with CBD (10mg i.p./kg per day), starting from the occurrence of the first signs of disease (14th day) until when mice have been sacrificed on the 28th day from EAE-induction, can avoid programmed cell death in the spinal cord of animals affected [69]. Finally, a model which is widely used for studying the chronic, demyelinating process in multiple sclerosis, is the Theilers murine encephalitis virus model (TMEV-induced demyelinating disease, TMEV-IDD), a naturally occurring single-stranded RNA-virus. In this model, mice were infected intracerebrally with TMEV and then treated with CBD (5mg i.p./ $\mathrm{kg}$ ) or the vehicle alone, once daily for up to 10 days post-infection to analyze the long-term effects. CBD completely blocked TMEV-induced release of the adhesion molecule VCAM- 1 which is mainly expressed by endothelial cells and that binds selectively to VLA-4 expressed by monocytes and lymphocytes; this significantly reduced the expression of the chemokines CCL2 and CCL5 transcripts and of IL-1ß. CBD treatment for 10 days in the acute phase of the disease attenuated neurodegeneration and demyelination in the chronic phase of TMEV-IDD, completely restoring both horizontal and vertical motor activities when on day 80 , motor function was evaluated [70].

In summary, although animal models do not necessarily correlate one-to-one to the therapeutic situation in man, it may be worth to try CBD in COVID-19 patients early when they start showing neurological symptoms. CBD reaches high concentrations in brain, has neuroprotective and anti-inflammatory properties, is well tolerated and can be combined with many other medications. Furthermore, it potentially limits stress, anxiety and other aftereffects.

\section{Acknowledgement}

None.

\section{Conflict of Interest}

Author declare no conflict of interest.

\section{References}

1. Bridwell R, Long B, Gottlieb M (2020) Neurologic complications of COVID-19. The American Journal of Emergency Medicine 38(7): 1549. e3-1549.e7.

2. Kandemirli SG, Dogan L, Sarikaya ZT, Kara S, Acinci C, et al. (2020) Brain MRI findings in patients in the intensive care unit with COVID-19 infection. Radiology.

3. Mao L, Wang M, Chen S, He Q, Chang J, et al. (2020) Neurological manifestations of hospitalized patients with COVID-19 in Wuhan, China: a retrospective case series study. JAMA Neurol 77(6): 1-9.

4. Munhoz RP, Pedroso JL, Nascimento FA, Almeida SM, Barsottini OGP, et al. (2020) Neurological complications in patients with SARS-CoV-2 infection: a systematic review. Brain, Behavior, \& Immunity - Health 5: 100094.

5. Roman GC, Spencer PS, Reis J, Buguet A, El Alaoui Faris M, et al. (2020) The neurology of COVID-19 revisited: A proposal from the Environmental Neurology Specialty Group of the World Federation of Neurology to implement international neurological registries. J Neurol Sci 414: 116884
6. Varga Z, Flammer AJ, Steiger P, Haberecker M, Andermatt R, et al. (2020) Endothelial cell infection and endotheliitis in COVID-19. Lancet 395(10234): 1417-1418

7. Yin R, Feng W, Wang T, Chen G, Wu T, et al. (2020) Concomitant neurological symptoms observed in a patient diagnosed with coronavirus disease 2019. J Med Virol.

8. Bulfamante G, Chiumello D, Canevini MP, Priori A, Mazzanti M, et al. (2020) First ultrastructural autoptic findings of SARS-Cov-2 in olfactory pathways and brainstem. Minerva Anestesiologica 86(6): 678-679.

9. Lechien JR, Chiesa-Estomba CM, Place S, Van Laethem Y, Cabaraux P, et al. (2020) Olfactory and gustatory dysfunctions as a clinical presentation of mild to moderate forms of the coronavirus disease (COVID-19): A multicenter European study. Eur Arch Otorhinolaryngol 277(8): 22512261.

10. Moein ST, Hashemian SMR, Mansourafshar B, Khorram-Tousi A, Tabarsi P, Doty RL (2020) Smell dysfunction: a biomarker for COVID-19. Int Forum Allergy Rhinol.

11. Epstein D, Andrawis W, Lipsky AM, Ziad HA, Matan M (2020) Anxiety and suicidality in hospitalized patient with COVID-19 infection. Eur J Case Rep Intern Med 7(5): 001651.

12. Huang Y, Zhao N (2020) Chinese mental health burden during the COVID-19 pandemic. Asian J Psychiatr 51: 102052.

13. Rogers JP, Chesney E, Oliver D, Pollak TA, McGuire P, et al. (2020) Psychiatric and neuropsychiatric presentations associated with COVID-19. Lancet Psychiatry 7(7): P611-627.

14. Troyer EA, Kohn JN, Hong S (2020) Are we facing a crashing wave of neuropsychiatric sequelae of COVID-19? Neuropsychiatric symptoms and potential immunologic mechanisms. Brain, Behavior, Immun 87:3439.

15.Zürcher SJ, Kerksieck P, Adamus C, Burr C, Lehmann AI, et al. (2020) Prevalence of mental health problems during virus epidemics in the general public, health care workers and survivors: A rapid review of the evidence.

16. Li Y, Wang M, Zhou Y, Chang J, Xian Y, et al. (2020) Acute cerebrovascular disease following COVID-19: a single centre, retrospective, observational study. Lancet.

17. Aggarwal G, Lippi G, Henry BM (2020) Cerebrovascular disease is associated with an increased disease severity in patients with Coronavirus Disease 2019 (COVID-19): A pooled analysis of published literature. Int J Stroke 15(4): 385-389.

18. Lodigiani C, Iapichino G, Carenzo L, Cecconi M, Ferrazzi P, et al. (2020) Venous and arterial thromboembolic complications in COVID-19 patients admitted to an academic hospital in Milan, Italy. Thromb Res 191: 9-14.

19. Avula A, Nalleballe K, Narula N, Sapozhnikov S, Dandu V, et al. (2020) COVID-19 presenting as stroke. Brain Behav Immun 87: 115-119.

20. Beyrouti R, Adams ME, Benjamin L, Cohen H, Farmer SF, et al. (2020) Characteristics of ischaemic stroke associated with COVID-19. J Neurol Neurosurg Psychiatry.

21. Goldberg MF, Goldberg MF, Cerejo R, Tayal AH (2020) Cerebrovascular disease in COVID-19. Am J Neuroradiol.

22.Helms J, Kremer S, Merdji H, Clere-Jehl R, Schenck M, et al. (2020) Neurologic Features in Severe SARS-CoV-2 Infection. N Engl J Med 382(23): 2268-2270.

23. Gonzalez-Pinto T, Luna-Rodriguez A, Moreno-Estebanez A, Agirre-Beitia G, Rodriguez-Antigüedad A, et al. (2020) Emergency Room Neurology in Times of COVID-19: Malignant Ischemic Stroke and SARS-COV2 Infection. Eur J Neurol.

24. Tunc A, Ünlübas Y, Alemdar M, Akyüz E (2020) Coexistence of COVID-19 and acute ischemic stroke report of four cases. J Clin Neurosci 77: 227229. 
25. Valderrama EV, Humbert K, Lord A, Frontera J, Yaghi S (2020) Severe acute respiratory syndrome coronavirus 2 infection and ischemic stroke. Stroke 51(7): e124-e127.

26. Abassi N, Ambegaonkar G (2019) Guillain-Barre syndrome: a review. Pediatrics \& Child Health 29(11): 459-462

27. Alter M (1990) The epidemiology of Guillain-Barré syndrome. Ann Neurol 27 Suppl: S7-S12.

28. Arnaud S, Budowski C, Ng Wing Tin S, Degosi B (2020) Post SARS-CoV-2 Guillain-Barré syndrome. Clinical Neurophysiol 131(7): 1652-1654.

29. Caamano DSJ, Beato RA (2020) Facial diplegia, a possible atypical variant of Guillain-Barré Syndrome as a rare neurological complication of SARS-CoV-2. J Clin Neurosci 77: 230-232.

30. Camdessanche JP, Morel J, Pozzetto B, Paul S, Tholance Y, et al. (2020) COVID-19 May Induce Guillain-Barré Syndrome. Revue Neurologique (Paris) 176(6): 516-518.

31. Coen M, Jeanson G, Almeida AC, Hübers A, Stierlin F, et al. (2020) GuillainBarré syndrome as a complication of SARS-CoV-2 infection. Brain Behav Immun 87: 111-112.

32. Molina AE, Martinez MM, Chueca PS, Lopez AC, et al. (2020) GuillainBarré syndrome associated with SARS-CoV-2 infection. Med Intensiva 4: S0210-S5691(20)30154-30156.

33. Otmani H, Moutawakil B, Rafai MA, Benna N, Kettani C, et al. (2020) Covid-19 and Guillain-Barré syndrome: more than a coincidence! Rev Neurol 176(6): 518-519.

34. Sedaghat Z, Karimi N (2020) Guillain Barré syndrome associated with COVID-19 infection: a case report. J Clin Neurosci 76: 233-235.

35. Toscano G, Palmerini F, Ravaglia S, Ruiz L, Invernizzi P, et al. (2020) Guillain-Barré Syndrome associated with SARS-CoV-2. N Engl J Med 382(26): 2574-2576.

36. Virani A, Raabold E, Hanson T, Haag A, Elrufay R, et al. (2020) GuillainBarré Syndrome associated with SARS-CoV-2 infection. IDCases 20 e00771.

37. Zhao H, Shen D, Zhou H, Liu J, Chen S (2020) Guillain-Barré syndrome associated with SARS-CoV-2 infection: causality or coincidence? Lancet Neurol 19(5): 383-384

38. Gutierrez-Ortiz C, Mendez A, Rodrigo-Rey S, Pedro-Murillo E, BermejoGuerrero L, et al. (2020) Miller Fisher Syndrome and polyneuritis cranialis in COVID-19. Neurology.

39. Filatov A, Sharma P, Hindi F, Espinosa PS (2020) Neurologica complications of Coronavirus disease (COVID-19): Encephalopathy. Cureus 12(3): e7352.

40. Chaumont H, Etienne P, Roze E, Couratier C, Roger PM, Lannuzel A (2020) Acute meningoencephalitis in a patient with COVID-19. Revue Neurol (Paris) 176(6): 519-521.

41. Moriguchi T, Harii N, Goto J, Harada D, Sugarawa H, et al. (2020) A first case of meningitis/encephalitis associated with SARS-Coronavirus-2. Int $\mathrm{J}$ Inf Dis 94: 55-58.

42. Poyiadji N, Shahin G, Noujaim D, Stone M, Patel S, Griffith B (2020) COVID-19-associated acute hemorrhagic necrotizing encephalopathy: CT and MRI. Radiology 201187.

43. Daou BJ, Koduri S, Palmateer G, Thompson BG, Chaudhary N, et al. (2020) Letter: Neurological implications of COVID-19 and lessons learned from prior epidemics and pandemics. Neurosurgery.

44. Richardson PJ, Ottaviani S, Prelle A, Stebbing J, Casalini G, Corbellino M (2020) CNS penetration of potential anti-COVID-19 drugs. J Neurol 267(7): 1880-1882.

45. England TJ, Hind WH, Rasid NA, O'Sullivan SE (2015) Cannabinoids in experimental stroke: a systematic review and meta-analysis. J Cerebral Blood Flow Metab 35(3): 348-358.
46. Hayakawa K, Mishima K, Fujiwara M (2010) Therapeutic potential of non-psychotropic cannabidiol in ischemic stroke. Pharmaceuticals (Basel) 3(7): 2197-2212.

47. Scharf EL (2017) Translating endocannabinoid biology into clinical practice: cannabidiol for stroke prevention. Cannabis Cannabinoid Res 2(1): 259-264.

48. Feng Y, Chen F, Yin T, Qian X, Yewei L, et al. (2015) Pharmacologic effects of cannabidiol on acute reperfused myocardial infarction in rabbits: evaluated with 3.0T cardiac magnetic resonance imaging and histopathology. J Cardiovasc Pharmacol 66(4): 354-363.

49. Gonca E, Darici F (2015) The effect of cannabidiol on ischemia/ reperfusion-induced ventricular arrhythmias: the role of adenosine A1 receptors. J Cardiovasc Pharmacol Ther 20(1): 76-83.

50. Walsh SK, Hepburn CY, Kane KA, Wainwright CL (2010) Acute administration of cannabidiol in vivo suppresses ischaemia-induced cardiac arrhythmias and reduces infarct size when given at reperfusion. Br J Pharmacol 160(5): 1234-1242.

51. Fouad AA, Al-Mulhim AS, Jresat I (2012) Cannabidiol treatment ameliorates ischemia/reperfusion renal injury in rats. Life Sci 91(7-8): 284-292.

52. Soares RZ, Vuolo F, Dall'Igna DM, Michels M, Crippa JA, et al. (2015) Evaluation of the role of the cannabidiol system in an animal model of ischemia/reperfusion kidney injury. Rev Bras Ter Intensiva 27(4): 383 389.

53. Alvarez FJ, Lafuente H, Rey-Santano MC, Mielgo VE, Gastiasoro E, et al (2008) Neuroprotective effects of the non-psychoactive cannabinoid cannabidiol in hypoxic-ischemic newborn piglets. Pediatr Res 64(6): 653-658.

54. Barata L, Arruza L, Rodriguez MJ, Aleo E, Vierge E, et al. (2019) Neuroprotection by Cannabidiol and Hypothermia in a Piglet Model of Newborn Hypoxic-Ischemic Brain Damage. Neuropharmacology 146: $1-11$.

55. Braida D, Pegorini S, Arcidiacono MV, Consalez GG, Croci L, et al. (2003) Post-ischemic treatment with cannabidiol prevents electroencephalographic flattening, hyperlocomotion and neuronal injury in gerbils. Neurosci Lett 346(1-2): 61-64.

56. Ceprian M, Vargas C, Barata L, Hind W, Martinez-Orgado J (2019) Cannabidiol administration prevents hypoxia-ischemia-induced hypomyelination in newborn rats. Front Pharmacol 10: 1131.

57. Eldemerdash NM (2014) Cannabidiol for Neuroprotection in Newborn Hypoxic-Ischemic Encephalopathy: pharmacological aspects and mechanisms of action. Thesis; Universidad de Madrid, Facultad de Medicina.

58. Lafuente H, Alvarez FJ, Pazos MR, Alvarez A, Rey-Santano MC, et al (2011) Cannabidiol reduces brain damage and improves functional recovery after acute hypoxia-ischemia in newborn pigs. Pediatr Res $70(3): 272-277$

59. Mohammed N, Ceprian M, Jimenez L, Pazos MR, Martinez-Orgado J (2017) Neuroprotective effects of cannabidiol in hypoxic ischemic insult. The therapeutic window in newborn mice. CNS Neurol Disord Drug Targets 16(1): 102-108.

60. Pazos MR, Cinquina V, Gomez A, Layunta R, Santos M, et al. (2012) Cannabidiol administration after hypoxia-ischemia to newborn rats reduces long-term brain injury and restores neurobehavioral function. Neuropharmacology 63(5): 776-783.

61. Valdizán EM, Pazos A, Martinez-Orgado J (2013) Mechanisms of cannabidiol neuroprotection in hypoxic-ischemic newborn pigs: Role of 5HT1A and CB2 receptors. Neuropharmacology 71: 282-291.

62. Hayakawa K, Irie K, Sano K, Watanabe T, Higuchi S, et al. (2009) Therapeutic time window of cannabidiol treatment on delayed ischemic damage via high-mobility group box1-inhibiting mechanism. Biol Pharm Bull 32(9): 1538-1544 
63. Khaksar S, Bigdeli MR (2017) Correlation between cannabidiol-induced reduction of infarct volume and inflammatory factors expression in ischemic stroke model. Basic Clinical Neurosci 8(2): 139-146.

64. Mishima K, Hayakawa K, Abe K, Ikeda T, Egashira N, et al. (2005) Cannabidiol prevents cerebral infarction via a serotonergic 5-hydroxytryptamine1A receptor (5-HT1A)-dependent mechanism. Stroke 36(5): 1077-1082.

65. Schiavon AP, Soares LM, Bonato JM, Milani H, Guimaraes FS, et al. (2014) Protective effects of cannabidiol against hippocampal cell death and cognitive impairment induced by bilateral common carotid artery occlusion in mice. Neurotox Res 26(4): 307-316.

66. Mori MA, Meyer E, Soares LM, Milani H, Guimaraes FS, et al. (2017) Cannabidiol reduces neuroinflammation and promotes neuroplasticity and functional recovery after brain ischemia. Prog Neuropsychopharmacol Biol Psychiatry 75: 94-105.

67. Elliott DM, Singh N, Nagarkatti M, Nagarkatti PS (2018) Cannabidiol attenuates experimental autoimmune encephalomyelitis model of multiple sclerosis through induction of myeloid-derived suppressor cells. Front Immunol 9: 1782.

68. Gonzalez-Garcia C, Torres IM, Garcia-Hernandez R, Campos-Ruiz L, Esparragoza LR, et al. (2017) Mechanisms of action of cannabidiol in adoptively transferred experimental autoimmune encephalomyelitis. Exp Neurol Dec 298(Pt A): 57-67.

69. Giacoppo S, Soundara Rajan T, Galuppo M, Pollastro F, Grassi G, et al. (2015) Purified Cannabidiol, the main non-psychotropic component of Cannabis sativa, alone, counteracts neuronal apoptosis in experimental multiple sclerosis. Eur Rev Med Pharmacol Sci 19(24): 4906-4919.

70. Mecha M, Feliu A, Inigo PM, Mestre L, Carrillo-Salinas FJ, et al. (2013) Cannabidiol provides long-lasting protection against the deleterious effects of inflammation in a viral model of multiple sclerosis: a role for A2A receptors. Neurobiol Dis 59: 141-150. 